\title{
Acridine Orange and Flow Cytometry: Which Is Better to Measure the Effect of Varicocele on Sperm DNA Integrity?
}

\author{
Essam-Elden M. Mohammed, ${ }^{1}$ Eman Mosad, ${ }^{2}$ Asmaa M. Zahran, ${ }^{2}$ \\ Diaa A. Hameed, ${ }^{3}$ Emad A. Taha, ${ }^{4}$ and Mohamed A. Mohamed ${ }^{5}$ \\ ${ }^{1}$ Dermatology and Andrology Department, Faculty of Medicine, Al-Azhar University, Assiut, Egypt \\ ${ }^{2}$ Clinical Pathology Department, South Egypt Cancer Institute, Assiut University, Assiut, Egypt \\ ${ }^{3}$ Urology Department, Faculty of Medicine, Assiut University, Assiut, Egypt \\ ${ }^{4}$ Dermatology and Andrology Department, Faculty of Medicine, Assiut University, Assiut, Egypt \\ ${ }^{5}$ Gynaecology and Obstetric Department, Faculty of Medicine, Al-Azhar University, Assiut, Egypt \\ Correspondence should be addressed to Essam-Elden M. Mohammed; dessam73@yahoo.com
}

Received 30 July 2015; Revised 22 October 2015; Accepted 25 October 2015

Academic Editor: Mohammad H. Ather

Copyright (C) 2015 Essam-Elden M. Mohammed et al. This is an open access article distributed under the Creative Commons Attribution License, which permits unrestricted use, distribution, and reproduction in any medium, provided the original work is properly cited.

\begin{abstract}
We evaluated the effect of varicocelectomy on semen parameters and levels of sperm DNA damage in infertile men. A total of 75 infertile men with varicocele and 40 fertile men (controls) were included in this study. Semen analysis and sperm DNA damage expressed as the DNA fragmentation index using acridine orange staining and chromatin condensation test by flow cytometry were assessed before and 6 months after varicocelectomy. The patients were also followed up for 1 year for pregnancy outcome. Semen parameters were significantly lower in varicocele patients compared to controls $(P<0.05)$. Mean percentages of sperm DNA fragmentation and sperm DNA chromatin condensation in patients were significantly higher than those in controls $(P<0.05)$. After varicocelectomy, sperm DNA fragmentation improved significantly, whereas sperm chromatin condensation was not significantly changed. In 15 out of 75 varicocele patients, clinical pregnancy was diagnosed; those with positive pregnancy outcome had significant improvement in sperm count, progressive sperm motility, and sperm DNA fragmentation, but there was no significant difference in sperm DNA condensation compared to negative pregnancy outcome patients. We concluded from this study that acridine orange stain is more reliable method than flow cytometry in the evaluation of sperm DNA integrity after varicocelectomy.
\end{abstract}

\section{Introduction}

Sperm DNA integrity is important for the transmission of genetic code, and it is considered as a marker of integrity of spermatogenesis and male fertility potential [1]. About $10 \%$ of the spermatozoa from fertile men and $20-25 \%$ of the spermatozoa from infertile men have measurable levels of DNA damage [2]. High levels of sperm DNA fragmentation (DFI) have been significantly associated with a bad pregnancy outcome [3-5].
Sperm DNA damage may be associated with many environmental conditions such as some medications, pollution, smoking, pesticides, chemicals, high temperature, and various pathologic cases such as cryptorchidism, fever, aging, infection, chemotherapy, cancer, and varicocele $[6,7]$.

The prognostic value of sperm DNA fragmentation is becoming better than the routine semen parameters, although the cut-off values of it are not established yet [8].

In this study, we evaluate the effect of varicocele on semen parameters and levels of sperm DNA integrity in infertile men 
with varicocele before and after varicocelectomy by acridine orange staining and flow cytometry.

\section{Materials and Methods}

From January 2012 to March 2015, a total of 75 men with at least 1-year history of infertility, a palpable varicocele, oligo, atheno, or teratozoospermia were selected from our andrology clinic. After the ethical committee approval, all the patients accepted to participate in the study and signed an informed consent. Forty healthy fertile volunteers (control group) were also included in this prospective study.

Patients were subjected to complete history taking and thorough general and local examination. Varicocele was detected clinically and confirmed by scrotal ultrasound (Fukuda Denshi Tellus UF-850XTD, Tokyo, Japan) equipped with color flow imaging when at least 1 scrotal vein had a maximum diameter of at least $3 \mathrm{~mm}$ and retrograde flow was observed at rest or after Valsalva maneuver. Grade 1 varicocele was diagnosed when reflux was measured at less than 1 second, grade II was diagnosed when reflux lasted 1-2 seconds, and grade III was diagnosed when reflux was noted at more than 2 seconds as described by Cornud et al. [9].

Semen samples were obtained by masturbation and collected in a sterile plastic container before and 3 months after subinguinal varicocelectomy with loop magnification that was done by either of the 3 surgeons with at least 7 years of experience. They were allowed to liquefy for $30 \mathrm{~min}$ at $37^{\circ} \mathrm{C}$, after which an analysis was performed to measure the following parameters: sperm concentration $/ \mathrm{mL}$, percentage of sperm motility, percentage of abnormal sperm morphology evaluated according to WHO guidelines [10].

2.1. Acridine Orange (AO) Assay. The AO assay measures the ability of sperm nuclear DNA to denature by acid which forms metachromatic shift of AO fluorescence from green (native DNA) to red (denatured DNA). The fluorochrome AO intercalates in double-stranded DNA as a monomer which binds to single-stranded DNA. The monomeric AO bound to native DNA fluoresce green, whereas the aggregated $\mathrm{AO}$ on denatured DNA fluoresces red [11].

The AO assay may be used for fluorescence microscopy or by flow cytometry. To perform this assay for fluorescent microscopy, thick semen layers are fixed in fixative (methanol:acetic acid 3:1) for 2 hours. The slides are stained for 5 minutes and rinsed with water. The slides were washed with distilled water then covered with glass cover and examined under a ZEISS mot plus (Germany) fluorescent microscope at the excitation wavelength of 450$490 \mathrm{~nm}$. An average of 200 sperm cells was evaluated on each slide by the same examiner. Spermatozoa which show green fluorescence were considered as normal DNA content, whereas sperms displaying a spectrum of yellow-orange to red fluorescence were considered to be with damaged DNA (Figure 1). The ratio between (yellow to red)/(green+yellow to red) fluorescence was considered as DFI percentages and the percentage of sample showing a ratio $<1$ was calculated in the group.

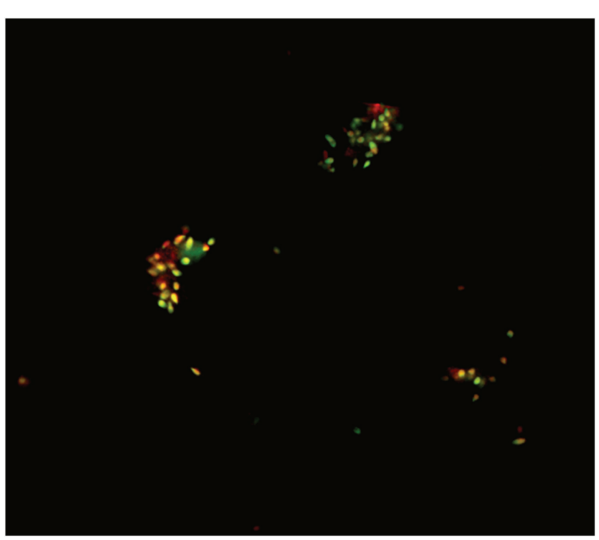

FIGURE 1: Fluorescence microscopy of acridine orange destained cells shows that spermatozoa displaying green fluorescence were considered to be with normal DNA content, whereas sperms displaying a spectrum of yellow-orange to red fluorescence were considered to be with damaged DNA. Original magnification $\times 200$.

\subsection{Flow Cytometric Detection of Sperm DNA Chromatin} Condensation. Flow cytometric detection of sperm DNA chromatin damage was made according to the method as described by Martinez-Soto et al. [12]. It depends on the fluorescence emission from sperm cells stained with propidium iodide (PI) that binds to DNA. The semen sample were diluted with phosphate buffered saline (PBS) to $2 \times$ $10^{6}$ sperm $/ \mathrm{mL}$. Fifty $\mu \mathrm{L}$ of semen sample was directly stained with $50 \mu \mathrm{g} / \mathrm{mL}$ PI, using the cycle test kit (Becton Dickinson, USA); PI was mixed with the semen and analyzed immediately by FACSCalibur flow cytometry with CellQuest software (Becton Dickinson Biosciences, USA). Ten thousand events were measured for each specimen; this permitted state of condensation of the sperm chromatin was analyzed, as the DNA condensation is directly related to PI uptake. The geometric mean fluorescence intensity (GMFI) was used to measure the degree of sperm DNA staining with PI. The sperm with altered nuclear condensation (DNA decondensation and fragmentation) takes more stains (Figure 2). These tests were performed on patients before and 3 months after varicocelectomy.

\section{Statistical Analysis}

The SPSS program, version 16.0.1 (SPSS Inc., Chicago, IL), was used in statistical analysis. The data were expressed as mean \pm SE and the differences were evaluated by paired $t$ test. Relationships between values were studied by Spearman correlation test. $P<0.05$ was set as statistically significant.

\section{Results}

Varicocele was detected by physical examination and confirmed by Doppler ultrasound in the 75 patients who entered the study. The mean age was 31 years (range: 20-57) for patients and 30.2 years (range: $21-37$ ) for controls. The main sperm characteristics of control and patients are shown in 


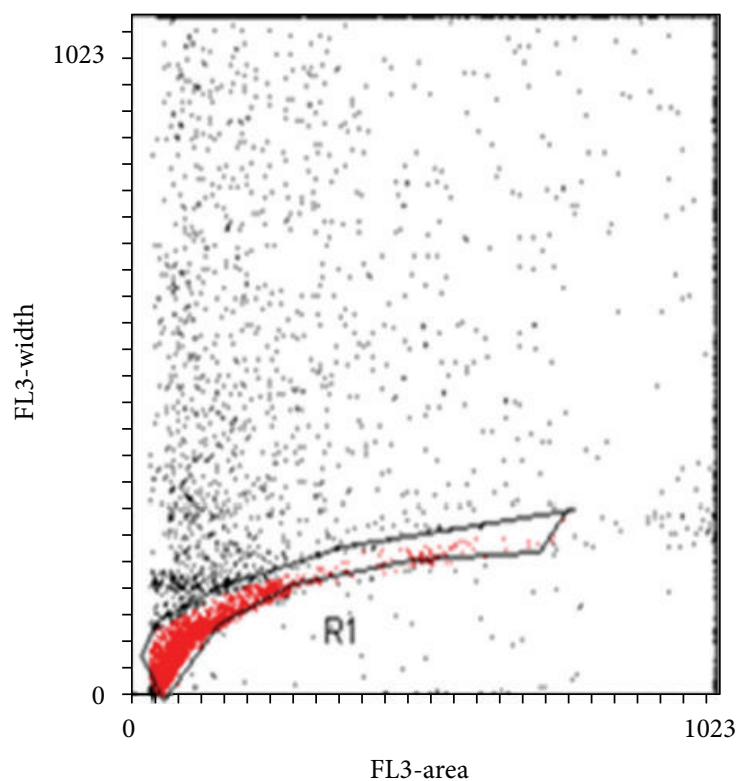

(a)

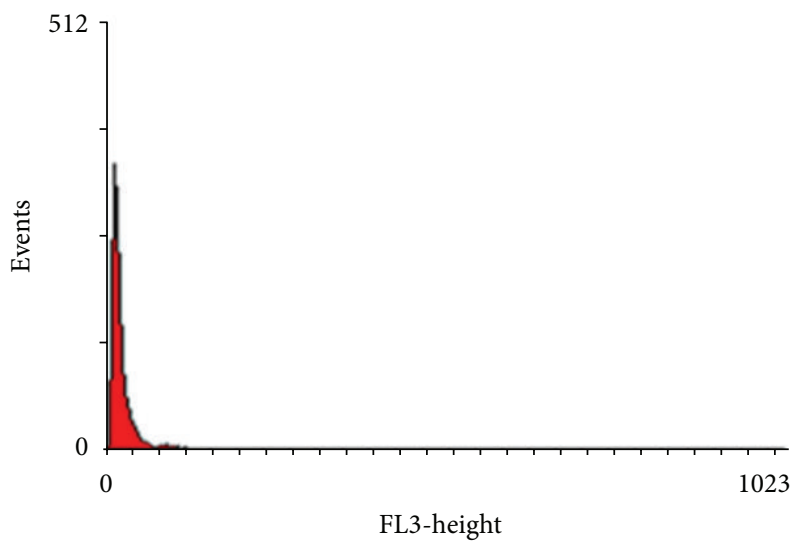

(b)

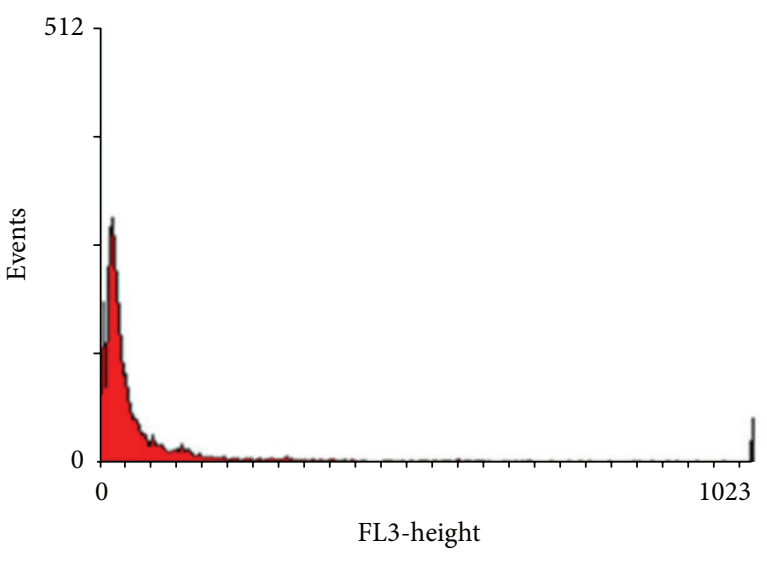

(c)

FIGURE 2: Flow cytometric detection of sperm DNA chromatin condensation. (a) Dot plot histogram (FL3A versus FL3W) obtained after propidium iodide staining of spermatozoa. Cells gated in R1 region were analyzed, while debris and aggregates were excluded from the analysis. The fluorescence intensity of cells (spermatozoa) was measured in R1 gate. (b) Histogram of fluorescence intensity of spermatozoa from normal control person. (c) Histogram of fluorescence intensity of spermatozoa from infertile person with varicocele.

Table 1. All patients had an abnormality in one or more of these parameters. There was a significant decrease in sperm concentration and percentage of progressive sperm motility and normal sperm morphology in varicocele patients compared to the controls (Table 1).

Comparisons of DFI results and GMFI between controls and patients with varicocele are shown in Table 1 . The mean values for DFI and GMFI of sperm DNA chromatin condensation in the control group were lower.

In patients with varicocele, DFI and GMFI had no correlation with sperm concentration, but they were negatively correlated with progressive motility and normal sperm morphology.

Sperm DNA fragmentation by acridine orange and sperm count changed significantly after varicocelectomy, but no significant changes were detected regarding sperm motility, morphology, and DNA chromatin condensation by flow cytometry (Table 2). In 15 out of 75 varicocele patients (20\%), clinical pregnancy (confirmed by ultrasound detection of fetal pulse) was achieved. Those with positive pregnancy outcome showed significant improvement in sperm count and sperm motility compared with negative pregnancy group $(P<0.05)$. Also, those with positive pregnancy outcome had significantly lower DNA fragmentation \% by acridine orange, but there is no significant difference in sperm DNA condensation by flow cytometry on comparing them to others who failed to make their partners conceive (Table 3 ).

\section{Discussion}

As it is well known [13-15], our study showed that the mean semen parameters were significantly lower in varicocele 
TABLE 1: Clinical and laboratory data of studied groups (mean \pm SD).

\begin{tabular}{|c|c|c|c|}
\hline Variables & Varicocele group $(n=75)$ & Fertile group $(n=40)$ & $P$ value \\
\hline Sperm count $(\mathrm{mil} / \mathrm{mL})$ & $26.2 \pm 2.7^{*}$ & $74.2 \pm 19.2$ & 0.005 \\
\hline Motility A + B (\%) & $27.8 \pm 16.5^{*}$ & $62.5 \pm 11.9$ & 0.02 \\
\hline Normal forms (\%) & $59.8 \pm 13.6^{*}$ & $71.03 \pm 8.2$ & 0.02 \\
\hline Sperm DFI (\%) by acridine orange & $32.4 \pm 7.4^{*}$ & $18.2 \pm 4.8$ & 0.003 \\
\hline GMFI of sperm DNA chromatin condensation by flow cytometry (\%) & $25.4 \pm 8.8^{*}$ & $12.8 \pm 2.2$ & 0.005 \\
\hline Mean age (years) & $31 \pm 8.2$ & $30.2 \pm 2$ & NS \\
\hline
\end{tabular}

* Significant $P<0.05$.

GMFI: the geometric mean fluorescence intensity.

DFI: DNA fragmentation index.

TABLE 2: Pre- and postvaricocelectomy semen parameters, sperm DFI, and GMFI of sperm DNA chromatin condensation by flow cytometry.

\begin{tabular}{|c|c|c|c|}
\hline Variables & Before varicocelectomy & After varicocelectomy & $P$ value \\
\hline Sperm count $(\mathrm{mil} / \mathrm{mL})$ & $26.2 \pm 2.7^{*}$ & $51 \pm 4.2$ & 0.05 \\
\hline Motility A + B (\%) & $27.8 \pm 16.5$ & $32 \pm 7$ & NS \\
\hline Normal forms (\%) & $59.8 \pm 13.6$ & $65.03 \pm 8.0$ & NS \\
\hline Sperm DFI (\%) by acridine orange & $32.4 \pm 7.4^{*}$ & $20 \pm 4.1$ & 0.05 \\
\hline GMFI of sperm DNA chromatin condensation by flow cytometry (\%) & $25.4 \pm 8.8$ & $22 \pm 4.1$ & NS \\
\hline
\end{tabular}

${ }^{*}$ Significant $P<0.05$.

TABLE 3: Comparison between those who achieved clinical pregnancy and those who failed after varicocelectomy.

\begin{tabular}{|c|c|c|c|}
\hline Variables & $\begin{array}{c}\text { Positive pregnancy after } \\
\text { varicocelectomy }(n=15)\end{array}$ & $\begin{array}{c}\text { No pregnancy after } \\
\text { varicocelectomy }(n=60)\end{array}$ & $P$ value \\
\hline Sperm count $(\mathrm{mil} / \mathrm{mL})$ & $59.4 \pm 5.3^{*}$ & $41 \pm 4.2$ & 0.04 \\
\hline Motility A + B (\%) & $40.2 \pm 17.5^{*}$ & $22.4 \pm 8.4$ & 0.03 \\
\hline Normal forms (\%) & $67.02 \pm 15.4$ & $63.46 \pm 11.0$ & NS \\
\hline Sperm DFI (\%) by acridine orange & $16.4 \pm 6.4^{*}$ & $24.2 \pm 4.1$ & 0.04 \\
\hline GMFI of sperm DNA chromatin condensation by flow cytometry (\%) & $20.3 \pm 6.8$ & $23.5 \pm 5.4$ & NS \\
\hline
\end{tabular}

* Significant $P<0.05$.

patients than in control group. The low sperm count may be due to the high apoptosis in the germ cell that occurs in varicocele, while the decreased motility may be due to the abnormal morphology of the sperm which affects its motility, the increased oxygen concentration of free radicals, or the antisperm antibodies [15].

Also, a large scale study by the WHO showed that infertile men with varicocele have lower sperm concentration significantly compared to idiopathic infertility, but it did not give any evidence regarding motility and morphology of the sperm [16]. Poor chromatin condensation has been correlated with numerous reproductive outcomes $[17,18]$. So DFI provides additional information about sperm quality and conception outcome $[18,19]$.

In our study, there was a high percentage of sperm with damaged DNA among patients with varicocele detected by $\mathrm{AO}$ and flow cytometry; this was well documented in the previous studies [20,21]. Having a higher percentage of sperm with damaged DNA assessed by AO staining suggests that increased DFI is one of the possible causes of infertility and can contribute to the higher prevalence of infertility among patients with varicocele $[15,22]$.
Several factors associated with varicocele may lead to DNA damage including heat, stress [23], exposure to toxic agents [24], testicular hypoxia [25], androgen deprivation [26], and increased oxidative stress [27].

The high percentage of sperm DFI in varicocele patients may be caused by an impaired chromatin condensation [28] Also, the nature of the nuclear damage could be related to a strong and prolonged exposure to DNA nuclear-damaging factors. Not only the DNA, but also the proteins of the nuclear matrix could lead to an advanced lytic stage [27].

Our results demonstrated that those with positive pregnancy outcome after varicocelectomy had significantly lower sperm DFI with acridine orange test than others who failed. A prospective study of infertile, oligospermic men with clinical varicocele who underwent surgical repair showed a significant improvement in postvaricocelectomy semen parameters and DFI [29]. A lower DFI was associated with higher spontaneous and ART pregnancy rates. Similarly, a positive effect of subinguinal microsurgical clinical varicocele repair on sperm DNA integrity and chromatin compaction (reflected by a significant decrease in sperm DFI and high DNA stainability, resp.) was reported in another prospective 
study [19]. In a study by [7, 18], the probability of fertilization in natural conception and in intrauterine insemination was found to be close to zero if the proportion of sperm cells with DNA damage exceeds $30 \%$ as detected by SCSA proposing the threshold for DFI $>30 \%$ in infertile men for poor ART outcome.In our study, we found that after varicocelectomy sperm count improved significantly, while the morphology and motility improvements did not reach statistical significance. Likewise, sperm DNA fragmentation by acridine orange not only improved significantly after varicocelectomy, but also correlated with positive pregnancy outcome, while the improvement measured by chromatin condensation by flow cytometry neither reached statistical significance nor correlated with positive pregnancy outcome.

After varicocelectomy, flow cytometry showed that the DFI was $22.5 \%$ of sperm DNA, which may be an accepted threshold for a successful ART outcome. This is comparable to the work of Pasqualotto et al. [5] who reported (27-30\%) DNA damage as a threshold for successful pregnancy.

In conclusion, the current study demonstrated an increase in sperm DFI in infertile patients with varicocele. After varicocelectomy, acridine orange test yielded significant results compared to flow cytometry that correlated with pregnancy outcome which suggests that it may be used as cheap and simple DNA integrity evaluation test for diagnostic and prognostic purpose in basic andrology laboratories.

\section{Conflict of Interests}

The authors declare that there is no conflict of interests that could be perceived as prejudicing the impartiality of the research reported.

\section{References}

[1] M. Benchaib, V. Braun, J. Lornage et al., "Sperm DNA fragmentation decreases the pregnancy rate in an assisted reproductive technique," Human Reproduction, vol. 18, no. 5, pp. 1023-1028, 2003.

[2] R. Smith, H. Kaune, D. Parodi et al., "Increased sperm DNA damage in patients with varicocele: relationship with seminal oxidative stress," Human Reproduction, vol. 21, no. 4, pp. 986993, 2006.

[3] M. Bungum, P. Humaidan, M. Spano, K. Jepson, L. Bungum, and A. Giwercman, "The predictive value of sperm chromatin structure assay (SCSA) parameters for the outcome of intrauterine insemination, IVF and ICSI," Human Reproduction, vol. 19, no. 6, pp. 1401-1408, 2004.

[4] D. T. Carrell, L. Liu, C. M. Peterson et al., "Sperm DNA fragmentation is increased in couples with unexplained recurrent pregnancy loss," Archives of Andrology, vol. 49, no. 1, pp. 49-55, 2003.

[5] F. F. Pasqualotto, D. P. A. F. Braga, R. C. S. Figueira, A. S. Setti, A. Iaconelli Jr., and E. Borges Jr., "Varicocelectomy does not impact pregnancy outcomes following intracytoplasmic sperm injection procedures," Journal of Andrology, vol. 33, no. 2, pp. 239-243, 2012.

[6] D. Sakkas, E. Mariethoz, and J. C. St. John, "Abnormal sperm parameters in humans are indicative of an abortive apoptotic mechanism linked to the Fas-mediated pathway," Experimental Cell Research, vol. 251, no. 2, pp. 350-355, 1999.

[7] D. P. Evenson and R. Wixon, "Comparison of the Halosperm test kit with the sperm chromatin structure assay (SCSA) infertility test in relation to patient diagnosis and prognosis," Fertility and Sterility, vol. 84, no. 4, pp. 846-849, 2005.

[8] M. B. Shamsi, S. N. Imam, and R. Dada, "Sperm DNA integrity assays: diagnostic and prognostic challenges and implications in management of infertility," Journal of Assisted Reproduction and Genetics, vol. 28, no. 11, pp. 1073-1085, 2011.

[9] F. Cornud, X. Belin, E. Amar, D. Delafontaine, O. Hélénon, and J. F. Moreau, "Varicocele: strategies in diagnosis and treatment," European Radiology, vol. 9, no. 3, pp. 536-545, 1999.

[10] World Health Organization, WHO Laboratory Manual for the Examination of Human Semen and Sperm-Cervical Mucus Interaction, Cambridge University Press, Cambridge, UK, 1999.

[11] K. Hoshi, H. Katayose, K. Yanagida, Y. Kimura, and A. Sato, "The relationship between acridine orange fluorescence of sperm nuclei and the fertilizing ability of human sperm," Fertility and Sterility, vol. 66, no. 4, pp. 634-639, 1996.

[12] J. C. Martinez-Soto, J. de Dioshourcade, A. Gutiérrez-Adán, J. L. Landeras, and J. Gadea, "Effect of genistein supplementation of thawing medium on characteristics of frozen human spermatozoa," Asian Journal of Andrology, vol. 12, no. 3, pp. 431-441, 2010.

[13] M. H. Schlesinger, I. F. Wilets, and H. M. Nagler, "Treatment outcome after varicocelectomy: a critical analysis," Urologic Clinics of North America, vol. 21, no. 3, pp. 517-529, 1994.

[14] I. Madgar, R. Weissenberg, B. Lunenfeld, A. Karasik, and B. Goldwasser, "Controlled trial of high spermatic vein ligation for varicocele in infertile men," Fertility and Sterility, vol. 63, no. 1, pp. 120-124, 1995.

[15] A. Agarwal, F. Deepinder, M. Cocuzza et al., "Efficacy of varicocelectomy in improving semen parameters: new metaanalytical approach," Urology, vol. 70, no. 3, pp. 532-538, 2007.

[16] P. D. Kantartzi, C. D. Goulis, G. D. Goulis, and I. Papadimas, "Male infertility and varicocele: myths and reality," Hippokratia, vol. 11, no. 3, pp. 99-104, 2007.

[17] A. D. Esterhuizen, D. R. Franken, J. G. H. Lourens, E. Prinsloo, and L. H. van Rooyen, "Sperm chromatin packaging as an indicator of in-vitro fertilization rates," Human Reproduction, vol. 15, no. 3, pp. 657-661, 2000.

[18] M. Spanò, J. P. Bonde, H. I. Hjøllund et al., "Sperm chromatin damage impairs human fertility," Fertility and Sterility, vol. 73, no. 1, pp. 43-50, 2000.

[19] A. Zini, A. Blumenfeld, J. Libman, and J. Willis, "Beneficial effect of microsurgical varicocelectomy on human sperm DNA integrity," Human Reproduction, vol. 20, no. 4, pp. 1018-1021, 2005.

[20] R. A. Saleh, A. Agarwal, R. K. Sharma, T. M. Said, S. C. Sikka, and A. J. Thomas Jr., "Evaluation of nuclear DNA damage in spermatozoa from infertile men with varicocele," Fertility and Sterility, vol. 80, no. 6, pp. 1431-1436, 2003.

[21] C. G. Blumer, R. M. Fariello, A. E. Restelli, D. M. Spaine, R. P. Bertolla, and A. P. Cedenho, "Sperm nuclear DNA fragmentation and mitochondrial activity in men with varicocele," Fertility and Sterility, vol. 90, no. 5, pp. 1716-1722, 2008.

[22] A.-F. Abdel-Maguid and I. Othman, "Microsurgical and nonmagnified subinguinal varicocelectomy for infertile men: a comparative study," Fertility and Sterility, vol. 94, no. 7, pp. 2600-2603, 2010. 
[23] L. Bujan and R. Mieusset, "Male contraception by testicular heating," Contraception Fertilite Sexualite, vol. 23, no. 10, pp. 611614, 1995.

[24] S. H. Benoff, C. Millan, I. R. Hurley, B. Napolitano, and J. L. Marmar, "Bilateral increased apoptosis and bilateral accumulation of cadmium in infertile men with left varicocele," Human Reproduction, vol. 19, no. 3, pp. 616-627, 2004.

[25] C.-C. Huang, R.-S. Chen, C.-M. Chen et al., "MELAS syndrome with mitochondrial tRNA(Leu(UUR)) gene mutation in a Chinese family," Journal of Neurology Neurosurgery and Psychiatry, vol. 57, no. 5, pp. 586-589, 1994.

[26] World Health Organization, "The influence of varicocele on parameters of fertility in a large group of men presenting to infertility clinics," Fertility and Sterility, vol. 57, no. 6, pp. 12891293, 1992.

[27] B. N. Hendin, P. N. Kolettis, R. K. Sharma, A. J. Thomas Jr., and A. Agarwal, "Varicocele is associated with elevated spermatozoal reactive oxygen species production and diminished seminal plasma antioxidant capacity," The Journal of Urology, vol. 161, no. 6, pp. 1831-1834, 1999.

[28] D. Sakkas, O. Moffatt, G. C. Manicardi, E. Mariethoz, N. Tarozzi, and D. Bizzaro, "Nature of DNA damage in ejaculated human spermatozoa and the possible involvement of apoptosis," Biology of Reproduction, vol. 66, no. 4, pp. 1061-1067, 2002.

[29] M. Smit, O. G. Wissenburg, J. C. Romijn, and G. R. Dohle, "Increased sperm DNA fragmentation in patients with vasectomy reversal has no prognostic value for pregnancy rate," The Journal of Urology, vol. 183, no. 2, pp. 662-665, 2010. 


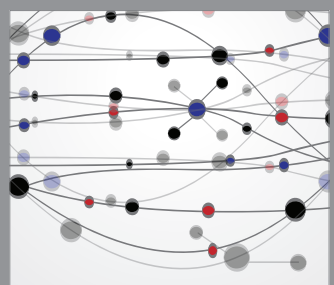

The Scientific World Journal
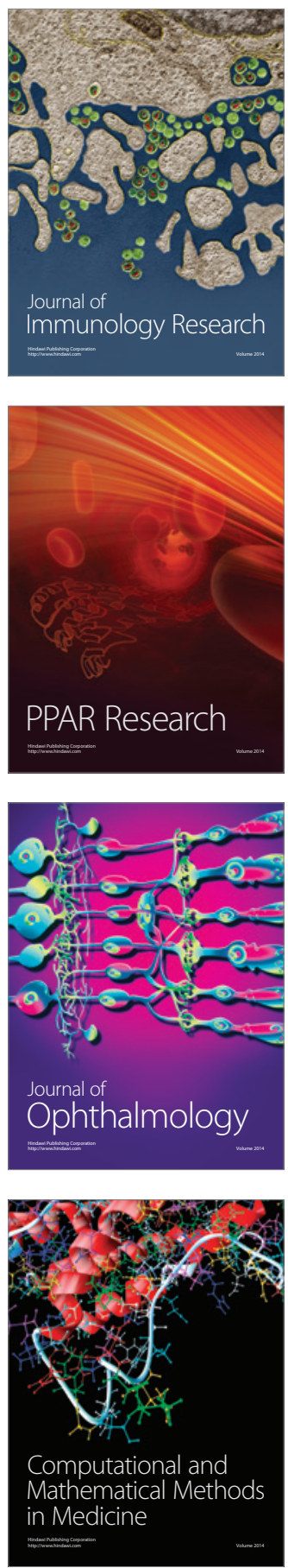

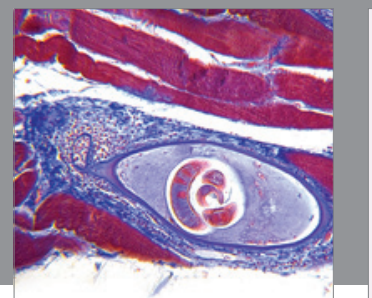

Gastroenterology

Research and Practice
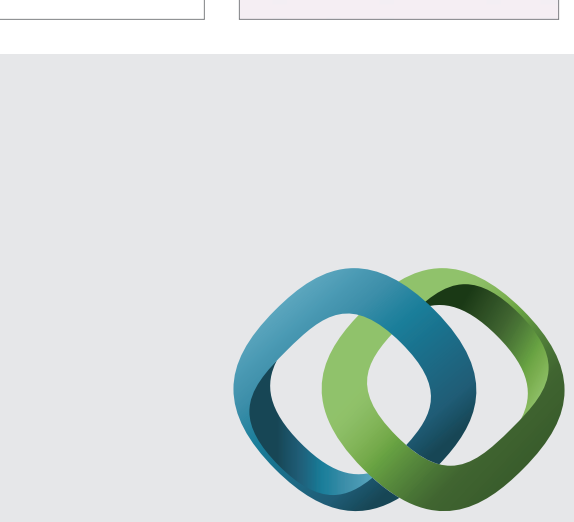

\section{Hindawi}

Submit your manuscripts at

http://www.hindawi.com
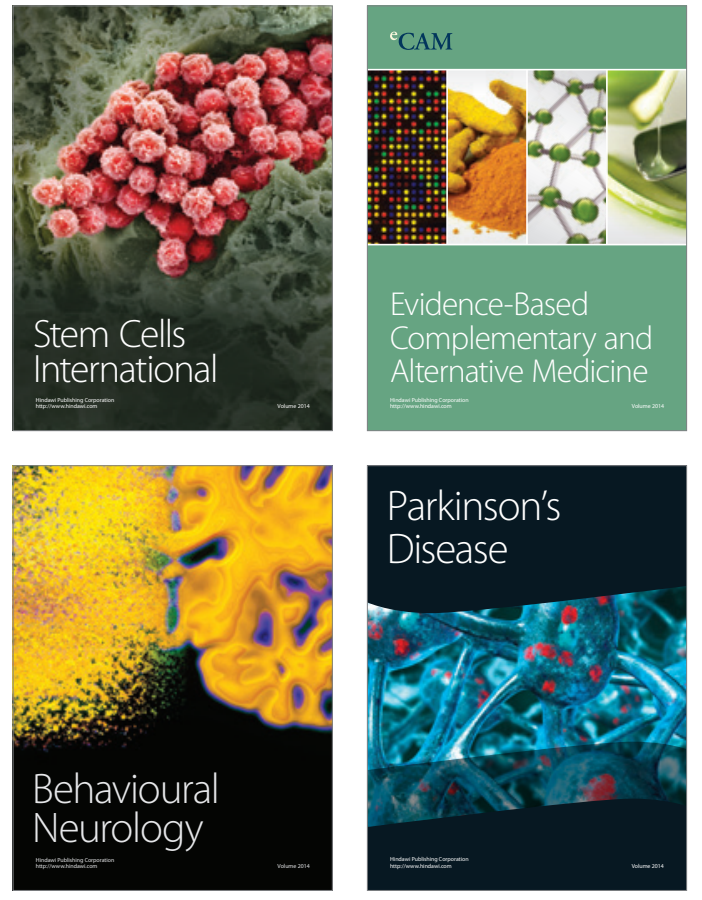
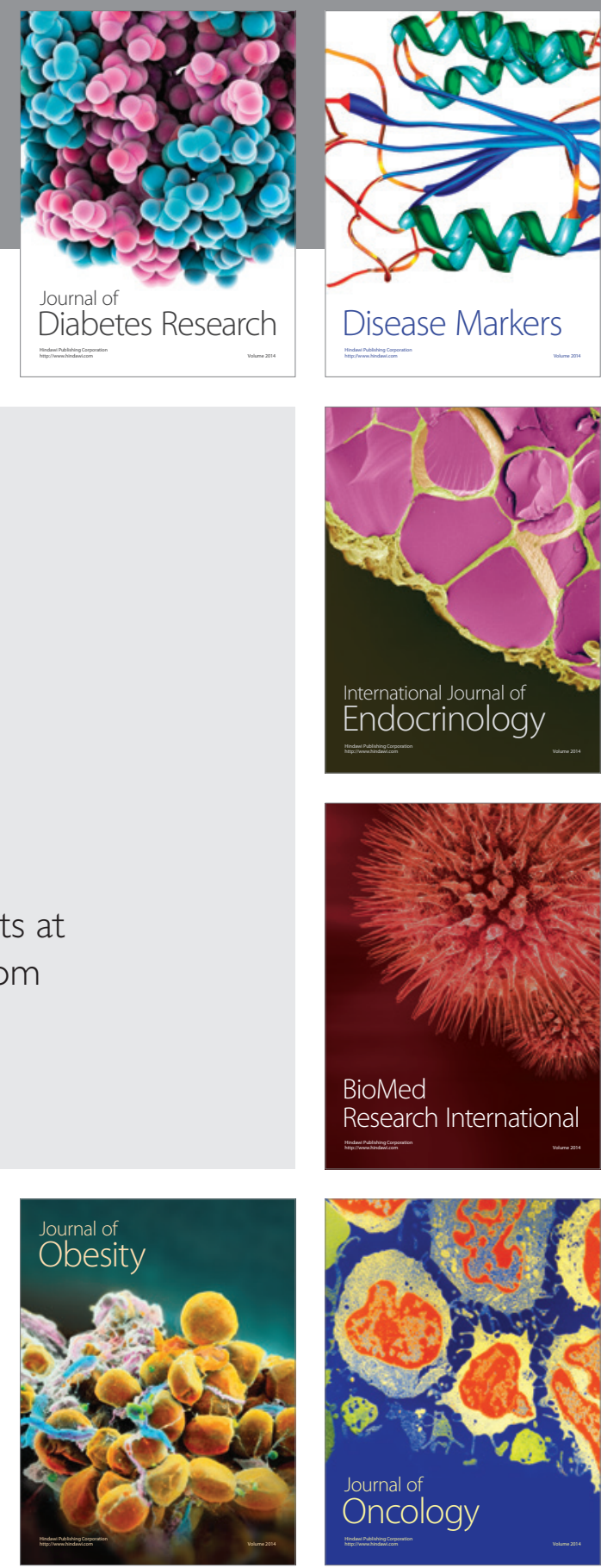

Disease Markers
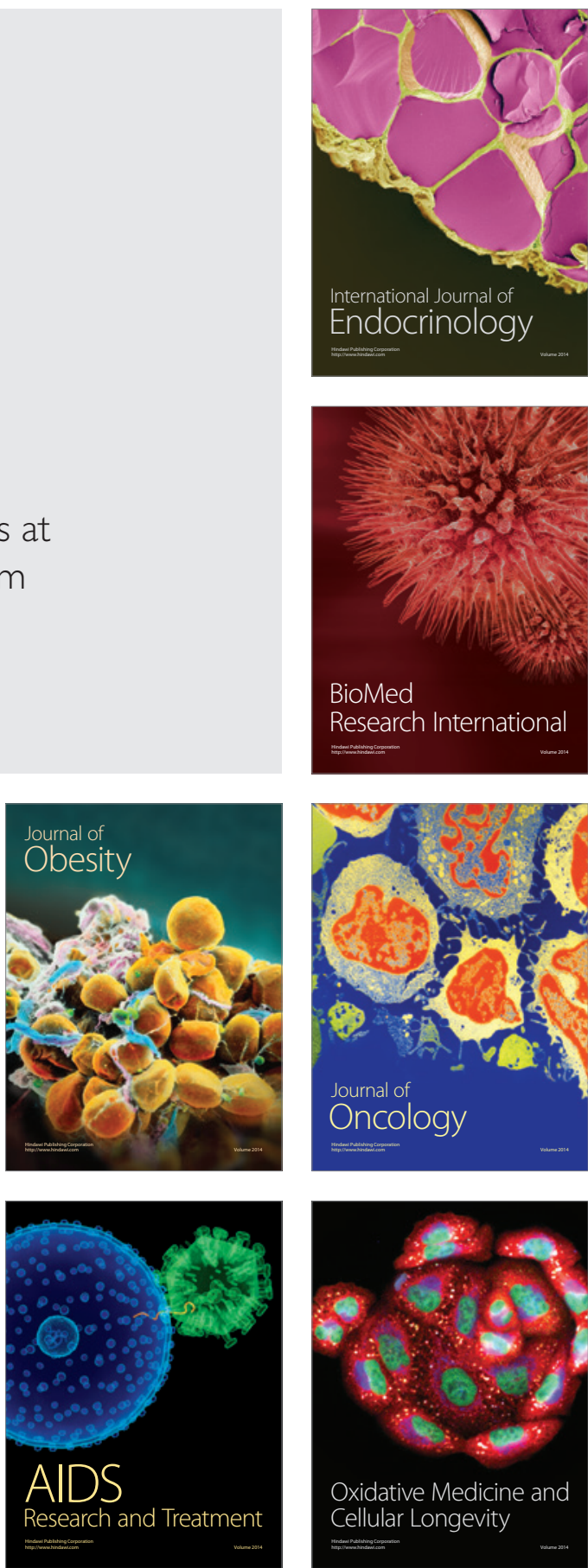